\title{
Impact of stand-alone minimally invasive radiofrequency ablation with left atrial appendectomy on left atrial function assessed by echocardiography
}

\author{
Yanjuan Zhang ${ }^{1 \#}$, Haoliang Sun ${ }^{2 \#}$, Mingfang $\mathrm{Li}^{1}$, Ming $\mathrm{Luo}^{2}$, Fang $\mathrm{Xu}^{1}$, Yongfeng Shao ${ }^{2}$, Di Xu ${ }^{3}$ \\ ${ }^{1}$ Department of Cardiology, ${ }^{2}$ Department of Cardiac Surgery, ${ }^{3}$ Department of Geriatrics, The First Affiliated Hospital of Nanjing Medical \\ University, Nanjing 210029, China
}

\#These authors contributed equally to this work.

Correspondence to: Di Xu, MD, PhD. Department of Geriatrics, The First Affiliated Hospital of Nanjing Medical University, Nanjing 210029 , China. Email: xudi@jsph.org.cn; Yongfeng Shao, MD, PhD. Department of Cardiac Surgery, The First Affiliated Hospital of Nanjing Medical University, Nanjing 210029, China. Email: shaoyongfeng2010@aliyun.com.

Background: Stand-alone minimally invasive radiofrequency (RF) ablation with left atrial (LA)
appendectomy has been an effective surgical intervention for non-paroxysmal atrial fibrillation (AF) (NPAF)
in patients with a medical history of thromboembolism for secondary stroke prevention. This study sought
to assess the impact of this surgery on LA function.

Methods: A total of $37 \mathrm{NPAF}$ patients with a medical history of stroke or thromboembolism were enrolled in this prospective observational study, all of whom underwent stand-alone minimally RF ablation with LA appendectomy. Echocardiography was used to evaluate LA function preoperatively and 1 week and 3 months postoperatively. All patients were divided into two groups (Group AF and Group SR) according to whether sinus rhythm (SR) was restored after the surgery.

Results: The surgery had no impact on LA function in Group AF. Once NPAF patients were restored to $\mathrm{SR}, \mathrm{LA}$ minimal volume $\left(\mathrm{LAV}_{\text {min }}\right)$ decreased immediately compared with pre-operation $(22.98 \pm 13.76 \mathrm{vs}$. $17.68 \pm 9.52 \mathrm{~mL} ; \mathrm{P}<0.05)$ and consequently LA reservoir function increased, including LAEF $(37.69 \% \pm 12.53 \%$ vs. $46.71 \% \pm 8.53 \%, \mathrm{P}<0.05)$ and LAEI $(66.54 \% \pm 34.39 \%$ vs. $92.15 \% \pm 31.37 \%, \mathrm{P}<0.05)$. PA-TDI of Group SR, indicating LA electromechanical coupling, were improved at three months of follow-up because of atrial stunning after the surgery $(160.55 \pm 26.19$ vs. $143.82 \pm 20.923 \mathrm{~ms}, \mathrm{P}<0.05)$. LA contractile function was also improved at three months of follow-up (A-TVI: $2.95 \pm 1.16$ vs. $5.10 \pm 1.85 \mathrm{~cm}, \mathrm{P}<0.05$ ).

Conclusions: Stand-alone minimal invasive RF ablation with LA appendectomy had no impact on LA function in AF patients who could not be restored to SR. However, once AF patients were restored to SR after the surgery, LA function could recover better. Meanwhile, thromboembolic events could also be reduced after the surgery.

Keywords: Surgery; non-paroxysmal atrial fibrillation (NPAF); left atrial function; thromboembolism

Submitted Aug 30, 2019. Accepted for publication Feb 18, 2020.

doi: $10.21037 /$ qims.2020.03.01

View this article at: http://dx.doi.org/10.21037/qims.2020.03.01

\section{Introduction}

Atrial fibrillation (AF) is a common arrhythmia disease in clinic practice (1). The most serious complication of
$\mathrm{AF}$ is thromboembolism, which leads to high morbidity and mortality rates in the general population (2). The left atrial (LA) appendage (LAA) is the most common site of 
thrombosis formation in patients with nonvalvular AF. In patients with $\mathrm{AF}$, anticoagulation drugs are used to prevent the onset of thromboembolism. However, these drugs also increase the risk of bleeding. Thus, it is important to weigh the advantages and disadvantages of anticoagulation drugs. Recently, thoracoscopic LA appendectomy was confirmed to be effective in preventing cardiogenic stroke (3). Radiofrequency (RF) energy applied through bilateral thoracoscopy in a procedure called stand-alone minimally invasive RF ablation was proven to be a useful and safe approach in the treatment of AF with cardiogenic stroke (4). In a 2013 systemic review, per the results from 23 observational studies involving 752 patients who underwent this surgery, the operative mortality rate was $0.4 \%$ and the complication rate was $3.2 \%$ (5). This surgery included both RF ablation and LAA resection. Some researchers have proposed that the LAA plays an important role in LA function, including in reservoir $(6,7)$, conduit (7), and contractile function (8). Elsewhere, other research supports that LAA resection did not negatively affect the cardiac function (9).

Previous studies have focused on changes in LA function with RF ablation (10) or simple LAA resection by thoracoscopic stand-alone LA appendectomy (9). The effect of stand-alone minimally invasive RF ablation on LA function remains unclear, while previous research suggests that postoperative LA function in $\mathrm{AF}$ patients holds a role in predicting AF recurrence (11). LA function includes reservoir function on systole, conduit function on early diastole, and contractile function on later diastole. Meanwhile, the total atrial conduction time (TACT) could help to facilitate future $\mathrm{AF}$ detection in patients with cryptogenic stroke (12). It is also a parameter of atrial function. The aim of our study was to explore the impact of this surgery on LA function.

\section{Methods}

\section{Patients}

Patients with non-paroxysmal AF (NPAF) between 18 and 80 years of age were selected on the basis of the following inclusion criteria from March 2017 to February 2018 in our institution: history of cerebrovascular events, high thromboembolic risk ( $\mathrm{CHA}_{2} \mathrm{DS}_{2}$-VASc score $\geq 3$ points), high bleeding risk (HAS-BLED score $\geq 3$ points), drug-refractory $\mathrm{AF}$, left ventricular ejection fraction of $50 \%$ or greater, able to provide written informed consent, life expectancy of at least 2 years, and able to attend scheduled follow-up visits.
In total, we enrolled 37 patients. All patients consented to undergo minimally invasive surgical treatment of their AF. The study protocol was approved by the institutional review board of Jiangsu Province Hospital. NPAF was defined as involving AF episodes lasting longer than 7 days according to the European Society of Cardiology guidelines (13). Prior to enrollment, all patients underwent cardiac structure and function evaluations by electrocardiography, 24hour Holter monitoring, and echocardiography. Patients with primary valvular heart disease, heart failure, severe pulmonary disease, uncontrolled arterial hypertension, uncontrolled thyroid disease, systemic inflammatory diseases, or poor echocardiographic visibility were excluded. Meanwhile, patients with LA thrombosis were excluded by transesophageal echocardiography or cardiac computed tomography. All patients underwent stand-alone minimally invasive RF ablation with LA appendectomy. Anticoagulants were discontinued after LA appendectomy. Amiodarone was administered for 3 months if the heart rate was more than $50 \mathrm{bpm}$ postoperatively. All enrolled patients visited the outpatient department for regular examinations. Postoperatively, 48-hour Holter monitoring and echocardiography were performed to evaluate resurgence of $\mathrm{AF}$ and LA function at 1 week and 3 months after surgery. Three months after surgery was chosen as a time point for evaluation because short atrial stunning was anticipated postoperatively to last about 4 to 6 weeks. During this period, the patient's condition may fluctuate greatly (14). Cardiac computed tomography and cranial magnetic resonance imaging were performed at 1 year post-operation to assess thromboembolic events, such as stroke, transient ischemic attack, and bleeding. Depending on whether sinus rhythm (SR) was restored after the surgery at 3 months, we stratified patients into two groups, Group $\mathrm{AF}(\mathrm{n}=15)$ and Group SR ( $\mathrm{n}=22)$.

\section{Surgical procedure}

The patients were placed in the supine position-albeit, modified to a bit higher by $15^{\circ}$ on the left lateral side. General anesthesia was administrated with a double-lumen endotracheal tube. Transesophageal echocardiography was performed to verify the absence of an LA thrombus before the procedure and adequacy of LAA excision at the end of the procedure. The chest was entered in the third, fourth, and sixth intercostal spaces using 5-, 5-, and 12-mm ports, respectively. On the right side, the first and third incisions are on the midaxillary line and the second incision is on the posterior axillary line. While on the left side, the first and 
third incision are on the anterior axillary line and the second incision is on the midaxillary line. The second incision was made for thoracoscopy and another two incisions were established for operating instruments. Insufflation was delivered at approximately $8 \mathrm{mmHg}$ to assist in resorptive atelectasis. A $10-\mathrm{mm} 30^{\circ}$ thoracoscope was introduced through the fourth intercostal. Thoracoscopy of the right side was done prior to the left side. The technique used was as originally described by Yilmaz et al. (15). The atrial rhythm was determined by placing the Max 3 bipolar pen (AtriCure Inc., Mason, OH, USA) on the LA and recordings were made using an electrophysiological analyzer (General Electric, Boston, MA, USA) (16). First, the pericardium was opened from the superior vena cava to inferior vena cava $1 \mathrm{~cm}$ anterior to the phrenic nerve. Blunt dissection of the right pulmonary veins was accomplished under thoracoscopic guidance. The isolation of right pulmonary veins was performed using a bipolar RF clamp (Atricure Inc., Mason, OH, USA) placed on the antrum of the pulmonary veins and three to six ablation lesions were established. A roof line and a floor line were created using the Max 3 bipolar pen (Atricure Inc., Mason, OH, USA) through the transverse and oblique sinuses. The procedure was repeated on the left side with the addition of division of the ligament of Marshall and exclusion of the LAA with liner cut staplers (Johnson \& Johnson, New Brunswick, NJ, USA). As a result, a box lesion (pulmonary vein isolation with roof and inferior lines) was created. The electrophysiology endpoint was entrance and exit block for the box lesion. If SR was not restored at the end of the procedure, a synchronized direct-current shock was applied for three times at maximum.

\section{Baseline data collection}

Baseline demographic and clinical data were collected for all patients, including age, height, weight, duration of AF, New York Heart Association class, $\mathrm{CHA}_{2} \mathrm{DS}_{2}$-VASc score, HASBLED score, and medical history.

\section{Echocardiography}

The GE VIVID E9 ultrasound instrument with an M5S probe was used along with an EchoPAC digital workstation (GE Healthcare, Chicago, IL, USA) for offline analysis.

All patients were placed in the left lateral decubitus position. All images were electrocardiogram-triggered and stored in a cine-loop format with five cardiac cycles. LA dimension (LAD) was measured in the parasternal longaxis view. Right atrial dimension (RAD) was measured in the apical four-chamber according to American Society of Echocardiography criteria (17). Mitral valve pulse-wave (PW) were acquired in the clip of the mitral valve. Tissue Doppler was applied on the septal and lateral walls on the mitral annulus level. E/e' was associated with left ventricular filling pressure in AF patients (18). LA volumes index were obtained from apical views by modified Simpson's rule and indexed to body surface area (BSA) according to the American Society of Echocardiography criteria (17).

\section{LA function}

LA phasic function can be described by changes in LA volume (19). The maximum LA volume occurs just before mitral valve opening $\left(\mathrm{LAV}_{\max }\right)$, minimum $\mathrm{LA}$ volume occurs at mitral valve closure $\left(\mathrm{LAV}_{\text {min }}\right)$, and $\mathrm{LA}$ volume at the onset of the P-wave on electrocardiography (LAV-p). LA emptying fraction (LAEF) and left expansion index (LAEI) reflect the LA reservoir function. LA active ejection fraction (LAAEF) represents LA contractile function. LA conduct function includes all blood volume flowing through the LA and could not be calculated only by changes in LA volume (19). Therefore, we used the LA conduit volume to evaluate LA conduit function. The formulae of these parameters are as follows:

$$
\begin{aligned}
& \mathrm{LAEF}=\left(\mathrm{LAV}_{\text {max }}-\mathrm{LAV}_{\text {min }}\right) / \mathrm{LAV}_{\text {max }} \\
& \mathrm{LAEI}=\left(\mathrm{LAV}_{\text {max }}-\mathrm{LAV}_{\text {min }}\right) / \mathrm{LAV}_{\text {min }} \\
& \mathrm{LAAEF}=\left(\mathrm{LAV}-\mathrm{p}-\mathrm{LAV}_{\text {min }}\right) / \mathrm{LAV}-\mathrm{p} .(19)
\end{aligned}
$$

For AF patients, only LA reservoir and conduit function could be assessed. Conversely, among those restored to SR after the surgery, we could also evaluate LA contractile function.

\section{Tissue Doppler and LA function assessment}

For those patients restored to SR, the recovery of LA contractile function was important. Buber et al. reported that the absence of LA mechanic contraction was independently associated with an increased risk for thromboembolic stroke (20). Besides being calculated by LA volume, TDI can also be used to assess LA contraction function (19). Trans-mitral peak velocity and time-velocity integral (TVI) of the early (E) and late (A) filling waves were measured in the apical four-chamber view. If the A-wave appeared, we observed its velocity and TVI to evaluate the recovery of LA contractile function. 


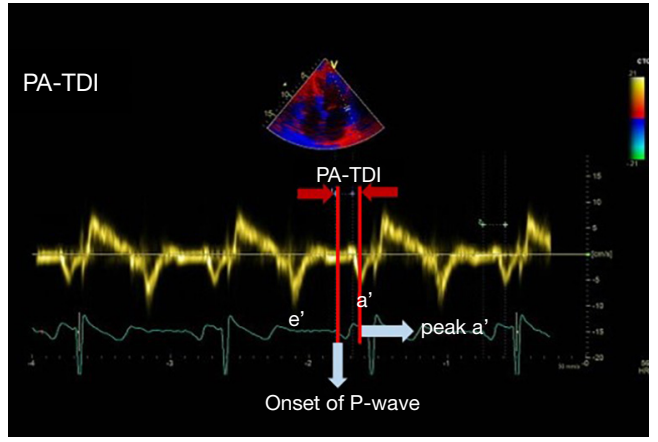

Figure 1 Measurement of PA-TDI (the interval of $\mathrm{P}$ wave and lateral a').

\section{TACT}

TACT can only be measured in SR. In the patients with SR after the surgery, we evaluated TACT to assess interatrial conductional function after surgery. To estimate TACT, the interval of $\mathrm{P}$ and lateral a' (PA-TDI) was measured. To assess the PA-TDI, we placed the cursor on the LA lateral wall just above the mitral annulus and measured the time interval between the onset of the P-wave in lead II on the electrocardiogram to the peak a'-wave (Figure 1).

\section{Statistical analysis}

Continuous variables are presented as means \pm standard deviations. Statistical analysis was performed using IBM SPSS 20.0 (IBM Corp, Armonk, NY, USA). The preoperative data of the two groups were compared by use of a $t$-test. Univariate repeated analysis of variance was used to compare preoperative and postoperative data between the two groups, respectively. The postoperative data of Group SR were compared by paired $t$-test. Finally, $\mathrm{P}$ values of less than 0.05 were considered to be statistically significant.

\section{Results}

\section{Baseline characteristic of all patients before surgery}

Table 1 lists the baseline information of all enrolled patients. Among 37 patients (mean age: 63.7 \pm 8.0 years), there were 25 male and 12 female patients whose duration of AF was $20.69 \pm 17.90$ months. Three patients $(8.11 \%)$ were diagnosed with hypertrophic cardiomyopathy (HCM), 21 patients (56.76\%) had hypertension, four patients $(10.81 \%)$ were diagnosed with coronary artery
Table 1 Baseline characteristic of all patients

\begin{tabular}{|c|c|}
\hline Parameters & CAF $(n=37)$ \\
\hline Age (year) & $63.7 \pm 8.0$ \\
\hline Male, n (\%) & $25(67.57)$ \\
\hline Weight (kg) & $70.69 \pm 11.83$ \\
\hline Height (cm) & $167.77 \pm 7.78$ \\
\hline $\mathrm{BSA}\left(\mathrm{m}^{2}\right)$ & $1.89 \pm 0.18$ \\
\hline $\mathrm{CHA}_{2} \mathrm{DS}_{2}-\mathrm{VASc}$ & $3 \pm 1.9$ \\
\hline HAS-BLED & $3.4 \pm 0.6$ \\
\hline Duration of AF (month) & $20.69 \pm 17.90$ \\
\hline \multicolumn{2}{|l|}{ NYHA class, n (\%) } \\
\hline I & $19(51.35)$ \\
\hline$>1$ & $18(48.65)$ \\
\hline HCM, n (\%) & $3(8.11)$ \\
\hline Hypertension, n (\%) & $21(56.76)$ \\
\hline CAD, n (\%) & $4(10.81)$ \\
\hline Diabetes, n (\%) & $5(13.51)$ \\
\hline
\end{tabular}

BSA, body surface aera; HCM, hypertrophy cardiomyopathy; $\mathrm{CAD}$, coronary heart disease.

disease through cardiac angiography, and five patients (13.51\%) had diabetes.

\section{$L A$ function in Group AF before the surgery and 1 week after and 3 months after the surgery}

Table 2 presents the echocardiographic parameters of Group AF before the surgery and 1 week and 3 months after surgery. There was no difference in LA size (including $\mathrm{LAD}$ and LA volume) or left function (reservoir function and conduit function). E/e' also showed no statistically significant difference.

\section{LA function in Group SR before the surgery, 1 week after, and 3 months after the surgery}

For patients in Group SR, there was no change seen in LAD or $\mathrm{LAVI}_{\max }$ between preoperation, 1 week postoperation, and 3 months postoperation. On the contrary, $\mathrm{LAVI}_{\min }$ was significantly decreased at 1 week after surgery when compared with preoperation (22.98 \pm 13.76 vs. $17.68 \pm 9.52 \mathrm{~mL} ; \mathrm{P}=0.011)$, although there was no significant change in $\mathrm{LAVI}_{\min }$ between 1 week and 
Table 2 Changes of parameters of left atrial size and function of Group AF pre-operation and 1 week and 3 months after surgery

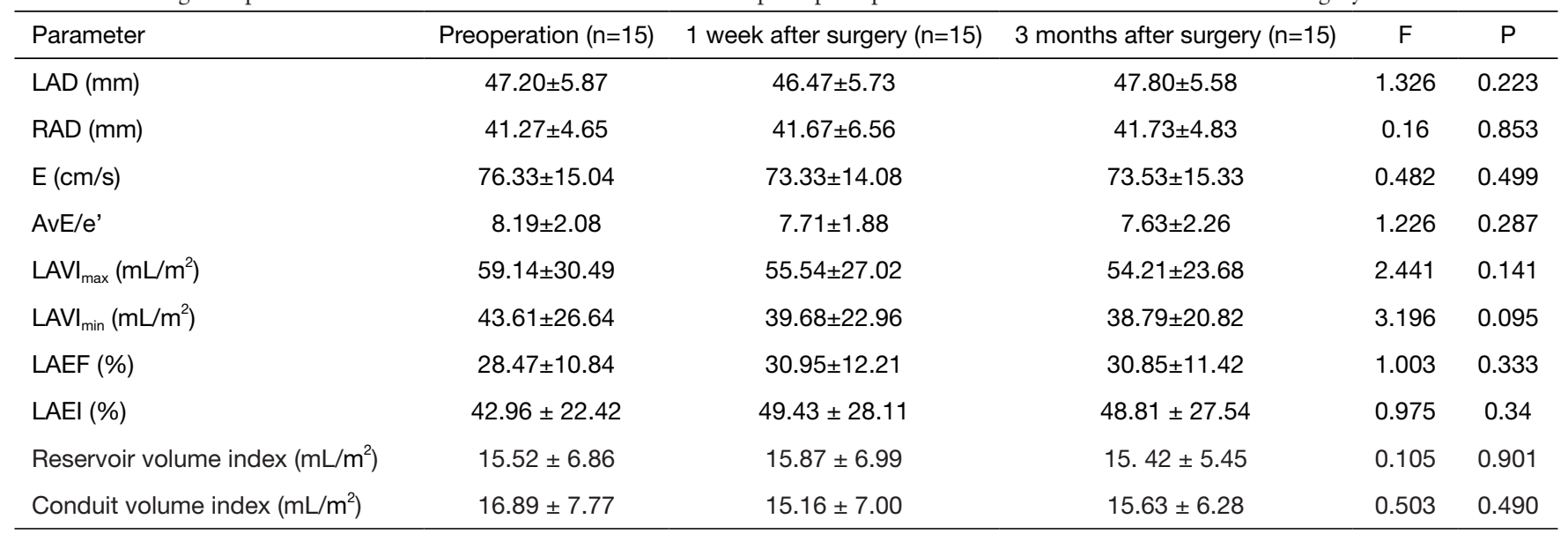

$L A D$, left atrial diameter; RAD, right atrial diameter; LAVI, left atrial volume index; LAEF, left atrial emptying fraction; LAEI, left atrial expansion index.

Table 3 Changes of parameters of left atrial size and reservoir and conduit function of Group SR pre-operation and 1week and 3months after surgery

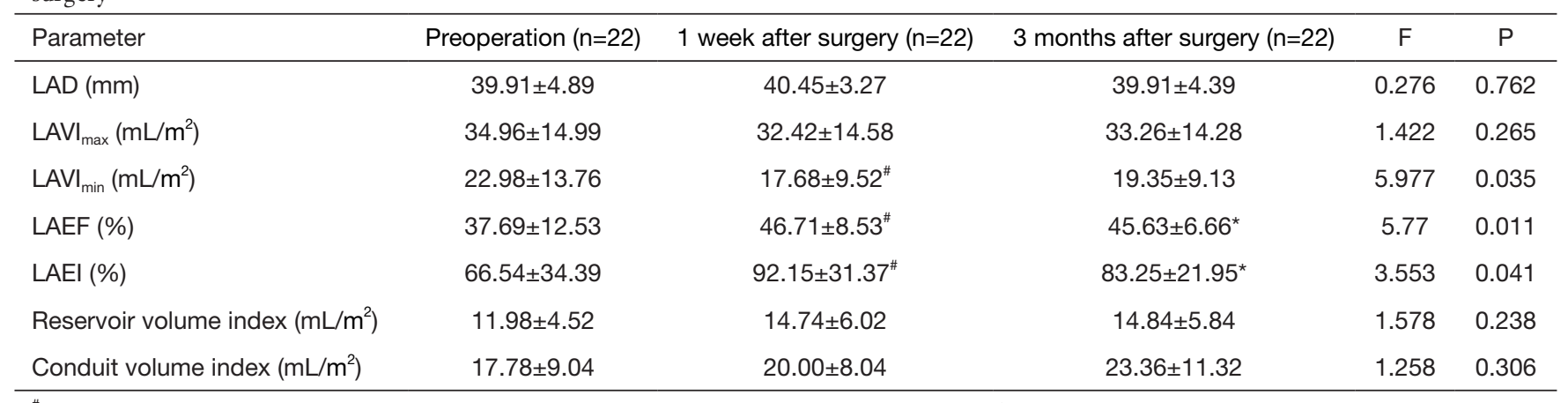

", compared with preoperation, $\mathrm{P}<0.05$; *, compared with preoperation, $\mathrm{P}<0.05$. LAD, left atrial diameter; RAD, right atrial diameter; LAVI, left atrial volume index; LAEF, left atrial emptying fraction; LAEI, left atrial expansion index.

3 months postoperation $(17.68 \pm 9.52$ vs. $19.35 \pm 9.13 \mathrm{~mL}$; $\mathrm{P}=0.476$ ). Because of reduced $\mathrm{LAVI}_{\min }, \mathrm{LAEF}$, and LAEI, reflecting reservoir function, were significantly increased at 1 week postoperation and maintained as such until 3 months postoperation, it is suggested that reservoir function increased immediately once the patient was restored to SR. Due to the reduction in $\mathrm{LAVI}_{\text {min }}$, reservoir volume and conduit volume were increased at 1 week postoperation, but showed no statistically significant difference relative to preoperation (Table 3).

Besides LA size, we should also pay more attention to the recovery of LA contractile function after surgery, which is important to left ventricular filling and cardiac output. Table 4 focused on the recovery of LA contractile function in Group SR after surgery. As soon as SR was restored in
AF patients, better LA contractile function immediately appeared, which was reflected in the rapid recovery of volume parameters such as LAAEF. However, improved recovery of contractile function was more dependent on parameters related to the electromechanical coupling of the LA such as total atrial conduction time and the appearance of the mitral valvular A-wave. In our study, it was found that the recovery of electromechanical activity of the LA occurred relatively slowly. PA-TDI was significantly shortened at 3 months post-operation when compared with 1 week after surgery $(160.55 \pm 26.19$ vs. $143.82 \pm 20.923 \mathrm{~ms}$; $\mathrm{P}=0.014)$. The peak of A-wave velocity and A-TVI caused by LA mechanical contraction were improved at 3 months from 1 week postoperation $(31.09 \pm 10.35$ vs. $48.91 \pm 13.32 \mathrm{~cm} / \mathrm{s}$; $\mathrm{P}=0.000$ and $2.95 \pm 1.16$ vs. $5.10 \pm 1.85 \mathrm{~cm} ; \mathrm{P}=0.000$ ). 
Table 4 Changes of parameters of left atrial contractile function and total conduction time of Group SR 1 week and 3 months after surgery

\begin{tabular}{lcccc}
\hline Parameter & 1 weeks $(\mathrm{n}=22)$ & 3 months $(\mathrm{n}=22)$ & $\mathrm{T}$ & $\mathrm{P}$ \\
\hline $\mathrm{E}(\mathrm{cm} / \mathrm{s})$ & $78.27 \pm 17.38$ & $80.73 \pm 22.37$ & -0.424 & 0.68 \\
$\mathrm{~A}(\mathrm{~cm} / \mathrm{s})$ & $31.09 \pm 10.35$ & $48.91 \pm 13.32$ & -11.553 & 0 \\
E/A & $2.67 \pm 1.07$ & $1.78 \pm 0.68$ & 4.335 & 0.001 \\
A-TVI (cm) & $2.95 \pm 1.16$ & $5.10 \pm 1.85$ & -6.890 & 0 \\
AvE/e' & $8.75 \pm 2.26$ & $8.81 \pm 2.43$ & -0.112 & 0.913 \\
PA-TDI (ms) & $160.55 \pm 26.19$ & $143.82 \pm 20.923$ & 2.983 & 0.014 \\
LAAEF (\%) & $27.269 \pm 9.102$ & $25.546 \pm 7.819$ & 0.567 & 0.583 \\
\hline
\end{tabular}

LAAEF, left atrial active emptying fraction.

\section{Discussion}

Stand-alone minimally invasive RF ablation with LA appendectomy had been reported to boast a success rate of $69 \%$ (95\% CI: $58-78 \%$ ) (5). In our research, however, the success rate was $59.5 \%$ possibly, due to the carefully selected study population.

Many studies have indicated that AF load is positively correlated with LA size and negatively with LA function (21). Therefore, the assessment of LA size and function is important among AF patients both preoperatively and postoperatively. The conclusions of this study are discussed below in detail.

\section{Effects of the surgery on LA function}

Some studies have postulated that LAA resection could lead to decreased LA reservoir and conduit function (7). However, in our study, we found that the LA reservoir and conduit function did not change regardless of whether the patient recovered to SR. The reason for this inconsistency with previous literature may be a difference in the patients enrolled and the variable methods used to evaluate LA function. In our study, we selected NPAF patients and some could not attain SR after the surgery, so the speckletracking imaging mentioned in previous studies could not be used. In order to have greater comparability, we used the change in LA volume parameters to evaluate LA function. It was found that LA appendectomy had no influence on LA reservoir or conduit function after the surgery in Group AF. Meanwhile, no clinical events, such as stroke, TIA, systemic thromboembolism, bleeding and call-cause mortality, happened during 1 year of follow-up after the surgery. This suggested that, for the same patients with NPAF, excision of the LAA may reduce the incidence of events. Previous literature has also reported that LAA excision could reduce thrombosis risk $(22,23)$. At the same time, all patients in this group received oral anticoagulation before the surgery and no anticoagulant was needed after the surgery, reducing the risk of bleeding.

In Group SR, it was found LA volume parameters, especially minimum volume of the LA, had changed significantly and decreased immediately at 1 week postoperation. Due to the reduction in the minimum volume, LAEF and LAEI, reflecting the reservoir function, both recovered to a good level at 1 week postoperation with no further significant change at three months postoperation. LA reservoir function played an important role in patients with $\mathrm{AF}$. One recent study proposed that the occurrence of unexplained stroke in patients with paroxysmal AF was related to a decline on LA reservoir function. LA reservoir function may provide more information besides $\mathrm{CHA}_{2} \mathrm{DS}_{2}$-VASc (24). Meanwhile, reservoir volume and conduit volume increased, although the difference was not statistically significant. From this point of view, only using volume to assess LA function is inadequate. We found that the minimum volume of the LA played an important role in the recovery of LA function in AF patients. It has been reported that LA minimum volume was more predictive of clinical cardiovascular adverse events than LA maximum volume $(25,26)$.

For patients in Group SR, LA contractile function immediately appeared after the surgery because we could successfully calculate the LAAEF on SR. It has been mentioned in one study that the average LAAEF in the normal population is $43 \% \pm 18.2 \%$ (27). In our study, LAAEF in Group SR was at the lowest level of the normal range at 1 week postoperation and experienced 
no significant change at 3 months postoperation. We calculated that volume parameters reflecting LA function were relatively insensitive to early predictions of disease relative to Doppler and strain analyses as was mentioned in a previous study (28). Therefore, to accurately evaluate the recovery of LA contractile function, we should also observe the recovery of LA electromechanical coupling.

In our study, PA-TDI was used to evaluate the recovery of LA electrical conduction and A-wave peak velocity and A-wave TVI of the mitral valve were considered to evaluate LA mechanical contraction.

It was found that electromechanical coupling of the LA was in an abnormal state at 1 week postoperation in our study. Indicators including PA-TDI, A-wave velocity, and A-wave TVI were all of low value, which may be related to atrial stunning (29). Atria stunning could be improved within a few minutes to 4 to 6 weeks, depending on the duration of $\mathrm{AF}$, atrial size, and presence or absence of structural heart disease. Of note, atrial stunning can lead to thromboembolism after cardioversion. We should pay close attention to patients during this period to prevent adverse events. In our research, patients were followed up with until 3 months postoperation to ensure sufficient time for atrial recovery. It was found that electromechanical coupling parameters were significantly better at this point than at only 1 week after surgery.

The extension of TACT was also a major mechanism of $\mathrm{AF}$, it has been reported that PA-TDI of more than $160 \mathrm{~ms}$ was related to the recurrence of AF (30). In our study, it was found that the mean value of P-TDI was greater than $160 \mathrm{~ms}$ at 1 week postoperation, which may be related to atrial stunning. P-TDI was significantly reduced at 3 months postoperation. Thus, the probability of recurrence of AF was reduced. It has also been reported that the recurrence of $\mathrm{AF}$ was significantly lower in patients with shorter $\mathrm{P}-\varepsilon \mathrm{CT}$ than those patients with persistently longer $\mathrm{P}-\varepsilon \mathrm{CT}$ for 6 months (31). This also indicates that TACT could play a guiding role in the recurrence of $\mathrm{AF}$ after the surgery.

A-wave velocity and A-wave TVI reflected the mechanical contraction of the LA. The absence of the A-wave was related to thromboembolism and the deterioration of heart failure (20). In our study, patients in Group SR all presented A-waves after the surgery. Meanwhile, these two parameters were significantly increased at 3 months postoperation when compared with 1 week postoperation. This could predict the low probability of thromboembolic events. It was suggested that parameters of the acute phase were not sensitive to predicting clinical events and could not be used to guide clinical decision-making.

\section{Recurrent thromboembolic events}

During 1 year of follow-up, no clinical events, including stroke, transient ischemic attack, bleeding, or systemic thromboembolism occurred in any of our patients and no positive findings on cardiac computed tomography and cranial magnetic resonance imaging were found.

\section{Limitations}

The limitations of this study are as follows: Firstly, few patients were enrolled. Secondly, since there was no preoperative control for LA contractile function of patients in Group SR, it was not possible to determine whether stand-alone minimally invasive $\mathrm{RF}$ ablation had an impact on LA contractile function.

\section{Conclusions}

Stand-alone minimally invasive RF ablation with LA appendectomy had no significant effect on LA size, LA function, or left ventricular diastolic function, even though it could not restore all patients to SR. Meanwhile, no thromboembolic events were observed in Group AF after the discontinuation of anticoagulant drugs during 1 year of follow-up, indicating that removal of the LAA could reduce thromboembolic events.

In NPAF patients restored to SR after the surgery, left reservoir function recovered. LA electromechanical coupling was in an abnormal state at 1 week postoperation due to atrial stunning but gradually recovered by 3 months postoperation. In our study, no thromboembolic events occurred during 1 year of follow-up, suggesting that the surgery was effective.

\section{Acknowledgments}

We thank LetPub (www.letpub.com) for its linguistic assistance during the preparation of this manuscript.

Funding: This study was supported by the National Natural Science Foundation of China (Grant No. 81871359) and by the National Natural Science Foundation of China (Grant No. 81974066).

\section{Footnote}

Conflicts of Interest: All authors have completed the ICMJE uniform disclosure form (available at http://dx.doi. org/10.21037/qims.2020.03.01). The authors have no 
conflicts of interest to declare.

Ethical Statement: The study protocol was approved by the institutional review board of Jiangsu Province Hospital.

Open Access Statement: This is an Open Access article distributed in accordance with the Creative Commons Attribution-NonCommercial-NoDerivs 4.0 International License (CC BY-NC-ND 4.0), which permits the noncommercial replication and distribution of the article with the strict proviso that no changes or edits are made and the original work is properly cited (including links to both the formal publication through the relevant DOI and the license). See: https://creativecommons.org/licenses/by-nc-nd/4.0/.

\section{References}

1. Chugh SS, Havmoeller R, Narayanan K, Singh D, Rienstra M, Benjamin EJ, Gillum RF, Kim YH, McAnulty JH Jr, Zheng ZJ, Forouzanfar MH, Naghavi M, Mensah GA, Ezzati M, Murray CJ. Worldwide epidemiology of atrial fibrillation: a Global Burden of Disease 2010 Study. Circulation 2014;129:837-47.

2. Andrade J, Khairy P, Dobrev D, Nattel S. The clinical profile and pathophysiology of atrial fibrillation: relationships among clinical features, epidemiology, and mechanisms. Circ Res 2014;114:1453-68.

3. Ohtsuka T, Ninomiya M, Nonaka T, Hisagi M, Ota T, Mizutani T. Thoracoscopic stand-alone left atrial appendectomy for thromboembolism prevention in nonvalvular atrial fibrillation. J Am Coll Cardiol 2013;62:103-7.

4. La Meir M, Gelsomino S, Luca F, Pison L, Chambille P, Parise O, Crijns HJ, Maessen JG. Time-related prevalence of postoperative atrial fibrillation after stand-alone minimally invasive radiofrequency ablation. J Card Surg 2011;26:453-9.

5. Krul SP, Driessen AH, Zwinderman AH, van Boven WJ, Wilde AA, de Bakker JM, de Groot JR. Navigating the mini-maze: systematic review of the first results and progress of minimally-invasive surgery in the treatment of atrial fibrillation. Int J Cardiol 2013;166:132-40.

6. Tabata T, Oki T, Yamada H, Iuchi A, Ito S, Hori T, Kitagawa T, Kato I, Kitahata H, Oshita S. Role of Left Atrial Appendage in Left Atrial Reservoir Function as Evaluated by Left Atrial Appendage Clamping During Cardiac Surgery. Am J Cardiol 1998;81:327-32.

7. De Maat GE, Benussi S, Hummel YM, Krul S, Pozzoli A, Driessen AH, Mariani MA, Van Gelder IC, Van Boven WJ, de Groot JR. Surgical Left Atrial Appendage Exclusion
Does Not Impair Left Atrial Contraction Function: A Pilot Study. Biomed Res Int 2015;2015:318901.

8. Lee CH, Kim JB, Jung SH, Choo SJ, Chung CH, Lee JW. Left atrial appendage resection versus preservation during the surgical ablation of atrial fibrillation. Ann Thorac Surg 2014;97:124-32.

9. Inoue T, Suematsu Y. Left atrial appendage resection can be performed minimally invasively with good clinical and echocardiographic outcomes without any severe risk. Eur J Cardiothorac Surg 2018;54:78-83.

10. Liżewska-Springer A, Dabrowska-Kugacka A, Lewicka E, Krolak T, Drelich L, Kozlowski D, Raczak G.

Echocardiographic assessment in patients with atrial fibrillation (AF) and normal systolic left ventricular function before and after catheter ablation: If $\mathrm{AF}$ begets $\mathrm{AF}$, does pulmonary vein isolation terminate the vicious circle? Cardiol J 2019. doi: 10.5603/CJ.a2019.0004.

11. Debonnaire P, Leong DP, Witkowski TG, Al Amri I, Joyce E, Katsanos S, Schalij MJ, Bax JJ, Delgado V, Marsan NA. Left atrial function by two-dimensional speckle-tracking echocardiography in patients with severe organic mitral regurgitation: association with guidelines-based surgical indication and postoperative (long-term) survival. J Am Soc Echocardiogr 2013;26:1053-62.

12. Müller P, Ivanov V, Kara K, Klein-Wiele O, Forkmann M, Piorkowski C, Blockhaus C, Dimitroulis D, Afzal S, Shin DI, Kelm M, Makimoto H, Mugge A. Total atrial conduction time to predict occult atrial fibrillation after cryptogenic stroke. Clin Res Cardiol 2017;106:113-9.

13. Camm AJ, Kirchhof P, Lip GY, Schotten U, Savelieva I, Ernst S, Van Gelder IC, Al-Attar N, Hindricks G, Prendergast B, Heidbuchel H, Alfieri O, Angelini A, Atar D, Colonna P, De Caterina R, De Sutter J, Goette A, Gorenek B, Heldal M, Hohloser SH, Kolh P, Le Heuzey JY, Ponikowski P, Rutten FH, Guidelines ESCCfP. Guidelines for the management of atrial fibrillation: the Task Force for the Management of Atrial Fibrillation of the European Society of Cardiology (ESC). Europace 2010;12:1360-420.

14. Graig T, January LSW, Joseph S. Alpert, Hugh Calkins. 2014 AHA/ACC/HRS Guideline for the Management of Patients With Atrial Fibrillation: A Report of the American College of Cardiology/ Americal Heart Association Task Force on Practice Guidelines and the Heart Rhythm Society. Circulation 2014;130:69.

15. Yilmaz A, Van Putte BP, Van Boven WJ. Completely thoracoscopic bilateral pulmonary vein isolation and left atrial appendage exclusion for atrial fibrillation. J Thorac Cardiovasc Surg 2008;136:521-2. 
16. Katritsis D, Ioannidis JP, Anagnostopoulos CE, Sarris GE, Giazitzoglou E, Korovesis S, Camm AJ. Identification and catheter ablation of extracardiac and intracardiac components of ligament of Marshall tissue for treatment of paroxysmal atrial fibrillation. J Cardiovasc Electrophysiol 2001;12:750-8.

17. Lang RM, Bierig M, Devereux RB, Flachskampf FA, Foster E, Pellikka PA, Picard MH, Roman MJ, Seward J, Shanewise JS, Solomon SD, Spencer KT, Sutton MS, Stewart WJ, Chamber Quantification Writing G, American Society of Echocardiography's G, Standards C, European Association of E. Recommendations for chamber quantification: a report from the American Society of Echocardiography's Guidelines and Standards Committee and the Chamber Quantification Writing Group, developed in conjunction with the European Association of Echocardiography, a branch of the European Society of Cardiology. J Am Soc Echocardiogr 2005;18:1440-63.

18. Al-Omari MA, Finstuen J, Appleton CP, Barnes ME, Tsang TS. Echocardiographic assessment of left ventricular diastolic function and filling pressure in atrial fibrillation. Am J Cardiol 2008;101:1759-65.

19. Hoit BD. Assessment of Left Atrial Function by Echocardiography: Novel Insights. Curr Cardiol Rep 2018;20:96.

20. Buber J, Luria D, Sternik L, Raanani E, Feinberg MS, Goldenberg I, Nof E, Gurevitz O, Eldar M, Glikson M, Kuperstein R. Left atrial contractile function following a successful modified Maze procedure at surgery and the risk for subsequent thromboembolic stroke. J Am Coll Cardiol 2011;58:1614-21.

21. Gupta DK, Shah AM, Giugliano RP, Ruff CT, Antman EM, Grip LT, Deenadayalu N, Hoffman E, Patel I, Shi M, Mercuri M, Mitrovic V, Braunwald E, Solomon SD, Effective aNticoaGulation with factor x AnGiAFTIMIESI. Left atrial structure and function in atrial fibrillation: ENGAGE AF-TIMI 48. Eur Heart J 2014;35:1457-65.

22. Melduni RM SH, Lee HC, Gersh BJ, Noseworthy PA, Bailey KR, Ammash NM, Cha SS, Fatema K, Wysokinski WE, Seward JB, Packer DL, Rihal CS, Asivatham SJ. impact of Left Atrial Appendage Closure duiring cardiac surgery on the occurrence of early postoperative atrial fibrillation, stroke, and mortality. circulation 2017;135:13.

23. Friedman DJ, Piccini JP, Wang T, Zheng J, Malaisrie SC, Holmes DR, Suri RM, Mack MJ, Badhwar V, Jacobs JP, Gaca JG, Chow SC, Peterson ED, Brennan JM. Association Between Left Atrial Appendage Occlusion and Readmission for Thromboembolism Among Patients With Atrial Fibrillation Undergoing Concomitant Cardiac
Surgery. JAMA 2018;319:365-74.

24. Obokata M, Negishi K, Kurosawa K, Tateno R, Tange S, Arai M, Amano M, Kurabayashi M. Left atrial strain provides incremental value for embolism risk stratification over CHA(2)DS(2)-VASc score and indicates prognostic impact in patients with atrial fibrillation. J Am Soc Echocardiogr 2014;27:709-16.e4.

25. Wu VC, Takeuchi M, Kuwaki H, Iwataki M, Nagata Y, Otani K, Haruki N, Yoshitani H, Tamura M, Abe H, Negishi K, Lin FC, Otsuji Y. Prognostic value of LA volumes assessed by transthoracic 3D echocardiography: comparison with 2D echocardiography. JACC Cardiovasc Imaging 2013;6:1025-35.

26. Russo C, Jin Z, Homma S, Rundek T, Elkind MSV, Sacco RL, Di Tullio MR. LA Phasic Volumes and Reservoir Function in the Elderly by Real-Time 3D Echocardiography: Normal Values, Prognostic Significance, and Clinical Correlates. JACC Cardiovasc Imaging 2017;10:976-85.

27. Anwar AM, Geleijnse ML, Soliman OI, Nemes A, ten Cate FJ. Left atrial Frank-Starling law assessed by realtime, three-dimensional echocardiographic left atrial volume changes. Heart 2007;93:1393-7.

28. Abu-Omar Y, Thorpe BS, Freeman C, Mills C, Stoneman VEA, Gopalan D, Rana B, Spyt TJ, Sharples LD, Nashef SAM. Recovery of Left Atrial Contractile Function After Maze Surgery in Persistent Longstanding Atrial Fibrillation. J Am Coll Cardiol 2017;70:2309-11.

29. Khan IA. Atrial stunning: basics and clinical considerations. Int J Cardiol 2003;92:113-28.

30. Chao TF, Sung SH, Wang KL, Lin YJ, Chang SL, Lo LW, $\mathrm{Hu}$ YF, Tuan TC, Suenari K, Li CH, Ueng KC, Wu TJ, Chen SA. Associations between the atrial electromechanical interval, atrial remodelling and outcome of catheter ablation in paroxysmal atrial fibrillation. Heart 2011;97:225-30.

31. Fujii A, Inoue K, Nagai T, Nishimura K, Uetani T, Suzuki J, Funada J, Okura T, Higaki J, Ogimoto A. Clinical Utility of Atrial Electromechanical Conduction Time Measured with Speckle Tracking Echocardiography after Catheter Ablation in Patients with Atrial Fibrillation: A Validation Study with Electroanatomical Mapping. Echocardiography 2016;33:1317-25.

Cite this article as: Zhang $\mathrm{Y}$, Sun $\mathrm{H}, \mathrm{Li} M$, Luo $\mathrm{M}, \mathrm{Xu}$ F, Shao Y, Xu D. Impact of stand-alone minimally invasive radiofrequency ablation with left atrial appendectomy on left atrial function assessed by echocardiography. Quant Imaging Med Surg 2020;10(5):970-978. doi: 10.21037/qims.2020.03.01 